\title{
A presidenta e a presidente - uma análise dos dados do Atlas Linguístico do Brasil nas capitais da Região Sul brasileira
}

\author{
The president and the president - an analysis of the data of the Brazilian Linguistic Atlas \\ in the capitals of the Brazilian South Region \\ Jacyra Andrade Mota* \\ Universidade Federal da Babia, Salvador, Bahia, Brasil \\ Sandra Cerqueira Pereira Prudencio** \\ Universidade Federal da Babia, Salvador, Bahia, Brasil
}

\begin{abstract}
Resumo: $\mathrm{O}$ presente estudo tem como objetivo verificar o comportamento linguístico de informantes do Atlas Linguistico do Brasil (ALiB) (CARDOSO et al., 2014) ao se referirem à forma feminina de presidente em seus usos variantes: a presidente e a presidenta. Os informantes considerados para este trabalho pertencem às capitais da região sul do Brasil, a saber: Curitiba, Florianópolis e Porto Alegre. O corpus pesquisado é composto de 24 inquéritos e seguem a metodologia do ALiB. Para melhor fundamentar as análises dos dados, foram consideradas as informações contidas nos compêndios que abordam o estudo da flexão de gênero na língua portuguesa, nas principais gramáticas da língua portuguesa, assim como em dicionários. Pesquisou-se ainda no recente trabalho monográfico de Santana (2016), realizado com inquéritos de cidades da capital e do interior da Região Nordeste, e verificou-se que o resultado, de uma forma geral, seguiu o mesmo direcionamento que o encontrado neste estudo. Por fim, afirma-se que os resultados obtidos nesta pesquisa apontam para a preferência pela variante não flexionada em gênero a presidente, embora a forma flexionada, presidenta, conste nos dados com quantidade significativa de ocorrências.
\end{abstract}

Palavras chave: ALiB. Variação. Morfologia.

\begin{abstract}
The purpose of the present study was to verify the linguistic behavior of the informers of Atlas Linguistico do Brasil (ALiB - Linguistic Atlas of Brazil) (CARDOSO et al., 2014) when referring to the feminine form of president and its variants: a presidente and a presidenta. The informants considered for this paper belong to the capitals of the southern region of Brazil, these being: Curitiba, Florianópolis and Porto Alegre. The researched corpus is composed of 24 surveys and follows the ALiB methodology. In order to substantiate the data analysis, information contained in the compendiums related to studies of gender inflection in the Portuguese language, in the main grammars of the Portuguese language, as well as in dictionaries was considered. A recent academic paper by Santana (2016) was also researched, which was carried out from surveys in cities of the capital and of the interior of the Northeastern Region, where it was verified that the results, in a general manner, accompanied the same direction of the present study. Finally, it is affirmed that the results obtained in the present research point out to a preference for the variant without the gender inflection a presidente, despite the fact that the inflected format, presidenta, is included in the information a significant number of times.
\end{abstract}

Keywords: ALiB. Variation. Morphology.

\section{INTRODUÇÃO}

Neste artigo propõe-se indicar e analisar os usos linguísticos dos informantes do ALiB das capitais da região sul do Brasil em relação à flexão ou à não flexão da forma presidente para designar a mulher que ocupa o cargo de presidência desse país.

A motivação para a realização da pesquisa deveu-se às discussões de cunho linguístico ocorridas no país após a eleição de Dilma Rousseff para assumir a liderança na Presidência da República Federativa do Brasil, especificamente, nas eleições realizadas em 31 de outubro de 2010. A partir de então, se iniciou uma polêmica de âmbito nacional em relação à forma

*Doutora, professora da Universidade Federal da Bahia, Bolsista Produtividade do CNPq. Email: jacymota@ufba.br. Orientadora.

**Estudante de doutorado do Programa de Pós-Graduação de Língua e Cultura da Universidade Federal da Bahia, bolsista CAPES. Email: sandraprudencio@uol.com.br. 
de como seria utilizado o nome presidente para se referir à representante desse cargo, já que se tratava de um fato inovador: uma mulher ocupar o mais alto cargo da nação brasileira.

A polêmica se fez diante da seguinte dúvida: o referido vocábulo deveria ser flexionado com o morfema de gênero (-a), formando o par: presidente, presidenta, ou se utilizaria o morfema latente para marcar o gênero desse vocábulo: o presidente, a presidente? fazendo uma "distinção de gêneros diferentes sem flexão", que, conforme Silva e Koch (2001), registra-se como forma alomórfica da tradicional flexão opositiva, no caso: presidente, presidenta.

No Brasil houve uma ampla discussão entre especialistas e leigos sobre esse assunto de teor linguístico, o que refletiu na circulação de muitos textos em jornais, telejornais, redes sociais, entre outros meios de comunicação, nos quais pessoas de todas as áreas debatiam sobre o emprego "correto" de uma forma ou outra para se referir a Dilma Rousseff, em seu cargo de presidir o país, o que se deu a partir de 01 de janeiro de 2011. Em certas oportunidades, ela mesma, em algumas entrevistas, afirmou que gostaria de ser chamada de a presidenta.

A possibilidade de utilização da forma presidente com flexão ou sem flexão cedeu espaço a um cenário dualizado quanto ao item em questão: de um lado a mídia popular, em geral e quase que completamente, referia-se à Dilma Rousseff como a presidente do Brasil, a presidente, a presidente Dilma, entre outros; por outro lado, a mídia oficial da presidência do Brasil, seja no rádio - Jornal do Brasil - ou na internet, no site Palácio do Planalto - Presidência da República referiam-se a ela como a presidenta do Brasil, a presidenta, entre outros. Nesse site, por exemplo, havia dois links denominados Café com a Presidenta e Conversa com a Presidenta em que constavam notícias atualizadas de sua atuação cotidiana política e cidadã. Complementando a linha seguida, os documentos oficiais do governo, assim como as notas oficiais, eram assinados pela Presidenta da República ou pela Presidenta da República Federativa do Brasil.

Salienta-se que essa escolha entre a forma flexionada e a não flexionada não acarreta problemas de comunicação entre os interlocutores, mas indica, em certas situações, identificações político-partidárias, ultrapassando o domínio de análise da linguística, especificamente, o da Sociolinguística, pois se adentra na Análise do Discurso e no âmbito da Sociologia.

\section{METODOLOGIA}

Diante desse contexto polêmico, em que se observa a liberdade dos falantes de poderem escolher a utilização de uma forma e outra, decidiu-se estudar esse assunto, inicialmente, em gramáticas e em dicionários e verificar o tratamento à flexão de presidente.

O estudo pauta-se na metodologia de pesquisa sociolinguística cujos conceitos envolvem a variação e a mudança linguísticas. Buscaram-se, nas falas de 24 informantes das três capitais da região sul do Brasil, participantes do projeto Atlas Linguístico do Brasil $(\mathrm{ALiB})$, as respostas à pergunta 09 do Questionário linguístico Morfossintático (QMS), que se refere, especificamente, a esse assunto, a saber: "Se na Presidência da República estivesse uma mulher, ela seria o quê?"

Poder-se-á obter, nesse estudo inicial, um pequeno retrato desse item tanto no que se refere ao que os gramáticos prescrevem como padrão normativo quanto no que os dicionários registram, assim como os relacionados às reflexões de linguistas, e o que dizem os informantes do ALiB, especificamente, os das capitais da região sul do Brasil: Curitiba, Florianópolis, Porto Alegre.

De acordo com a metodologia do projeto $\mathrm{ALiB}$, foram aplicados inquéritos linguísticos a falantes das três capitais da região Sul com as seguintes características: homem e mulher; 
de duas faixas etárias: 18 a 30 anos e 50 a 65 anos; de dois níveis de escolaridade: fundamental I e universitário.

Com os dados coletados, foi realizada uma análise das variantes linguísticas em questão, conforme se apresentam nos informantes, especificamente quanto à flexão de gênero do vocábulo presidente, conciliando-a com as variáveis independentes sexo, faixa etária e escolaridade, segundo os princípios da teoria sociolinguística. Foi feito o controle das respostas por localidade, em que se pôde ainda verificar o comportamento linguístico dos informantes por cidade/capital, apresentando os dados de acordo com a sua distribuição e a variação diatópica, obtendo uma visão tanto no eixo que comporta os fatores sociais idade, gênero, escolaridade, como no eixo do espaço geográfico, o diatópico.

Os inquiridores realizaram a pergunta de forma direta e as respostas ocorreram imediatamente em uns inquéritos ou, em outros, foram obtidas por meio de desdobramentos das questões realizadas.

Especificamente no eixo da faixa etária, em que se têm os dados apresentados por informantes de duas faixas, buscam-se indícios de mudança em tempo aparente, com interpretações significativas que forneçam uma fotografia linguística a respeito das formas presidente/presidenta. Com isso, teremos um estudo dos usos linguísticos dos informantes do ALiB, cujos inquéritos foram realizados em um mesmo tempo de língua, de 2001 a 2012.

Para o cômputo das respostas, salienta-se que se considerou um ou outro item presidenta ou presidente -, mesmo que o informante tenha citado os dois no inquérito. Nesses casos, fez-se a interpretação da resposta para decidir qual seria considerado.

Seguem adiante considerações constantes em gramáticas e em dicionários a respeito da flexão de gênero de presidente.

\section{O QUE NOS DIZEM AS GRAMÁTICAS E OS DICIONÁRIOS DA LÍNGUA PORTUGUESA SOBRE PRESIDENTE/PRESIDENTA?}

Para o estudo deste assunto, foram consultadas três gramáticas, a fim de verificar se há observações relevantes a respeito de Presidente/Presidenta.

Em a Moderna Gramática Portuguesa, Evanildo Bechara, na seção O Gênero nas Profissões Femininas observa que a presença das mulheres em atividades profissionais faz com que a língua se ajuste a essa realidade e assim seus falantes usem termos como: advogada, engenheira, professora, entre outros. Tratando de denominações para cargos, como é o caso de presidenta, o autor informa que "[...] algumas formas femininas podem não vingar por se revestirem de sentido pejorativo: chefa, caba, por exemplo." (BECHARA, 2009, p. 134). Em Formação do Feminino, o autor trata de dois tipos de vocábulos com vogal temática -e: os que são invariáveis em relação à flexão de gênero e os que se comportam com variação; para o primeiro tipo, cita como exemplo cliente e para o segundo, o par presidente - presidenta, ressalvando que, assim como parente - parenta, dentre outros, esses usos flexionados também aparecem como invariáveis, ou seja, não flexionados. De acordo com esse autor, o uso de presidenta varia entre flexionar e não flexionar, pelos motivos expostos acima.

Em a Nova Gramática do Português Contemporâneo, Cunha e Cintra em Regras Especiais, da seção Formação do Feminino afirmam que "[...] os substantivos terminados em -e [...] são geralmente uniformes [...] Há, porém, um pequeno número que, à semelhança da substituição do -o (masculino) por -a (feminino) troca o -e por -a" (CUNHA; CINTRA, 1985, p. 188) e citam como exemplo parente - parenta, dentre outros. Em Observação, afirmam que o uso de presidenta tem ainda um curso restrito na língua. Para presidenta, vê-se, nas duas gramáticas consultadas, sem deixar de levar em consideração o hiato entre os anos de publicação de cada obra, que o uso de presidenta possui o status de restrito, em Cunha e Cintra (1985) e de uso oscilante, em Bechara, (2009), o que parece ser, de certa forma, um 
excelente indício de ampliação do uso do item, fato concluído a partir da consulta a essas duas gramáticas tradicionais.

Marcos Bagno, na Gramática Pedagógica do Português Brasileiro, traz uma reflexão interessante sobre o assunto, que se respalda nas entradas dos vocábulos nos dicionários. Para o autor, palavras como "Coelho e coelha não são duas formas da mesma palavra, mas palavras lexicais distintas que os dicionários registram separadamente" (BAGNO, 2011, p. 687). Trata-se, portanto, de uma derivação lexical, afirmação que é sustentada por ele com a explicação do uso de chefa, sargenta, presidenta: "são frequentemente encarados como opções pessoais ou escolhas estilísticas dos falantes, o que não acontece quando estamos diante de uma flexão regular" (BAGNO, 2011, p. 687). Com a afirmação de Bagno, vê-se que as suas ideias não destoam das dos autores anteriores, o que nos faz entender que, nas três gramáticas consultadas, a forma presidenta é considerada como possível de ser realizada, mas vacilante em sua utilização e que não há afirmações categóricas nem de uso nem de não uso do termo em questão.

Ao Consultar o Grande dicionário Houaiss da língua portuguesa, em meio eletrônico, verifica-se que presidenta tem entrada nessa obra, com data de registro estimado de 1872 e a seguinte definição: substantivo feminino. 1.: Mulher que exerce o cargo de presidente de uma instituição.

No Dicionário eletrônico Michaelis Moderno Dicionário da Lingua Portuguesa, há também a entrada para Presidenta: $\mathbf{s f}$ (fem de presidente) 1 Esposa do presidente. 2 Mulher que preside.

Como se pôde verificar na consulta às gramáticas e aos dicionários, há registros de presidenta e os falantes que optam pela realização flexionada estão respaldados por gramáticos e dicionaristas tanto quanto os que escolhem utilizar a presidente, pois não foi encontrada informação categórica em relação aos usos de uma e/ou de outra forma. Destaca-se que o Michaelis já traz explicitado que se trata de feminino de presidente.

\section{ANÁLISE DOS DADOS}

Para a análise dos dados, separaram-se todas as respostas dos informantes, considerando que houve algumas variações no que se refere ao sintagma.

Para presidente ocorreram 16 respostas que assim se realizaram: Uma presidente da repúbrica, presidente da república, uma presidente, presidente, a presidente, a presidente do Brasil. Para presidenta, houve oito respostas realizadas como presidenta e uma presidenta. Segue a representação em quadro e em gráfico do quantitativo das respostas.

\begin{tabular}{|c|c|c|}
\multicolumn{2}{c}{ Quadro 01 - Resultado Geral I } \\
\hline ITEM & OCORRÊNCIA & PORCENTAGEM \\
\hline Presidenta & 08 & $33 \%$ \\
\hline Presidente & 16 & $67 \%$ \\
\hline Total & & \\
\hline
\end{tabular}

Fonte: Dados da pesquisa. 


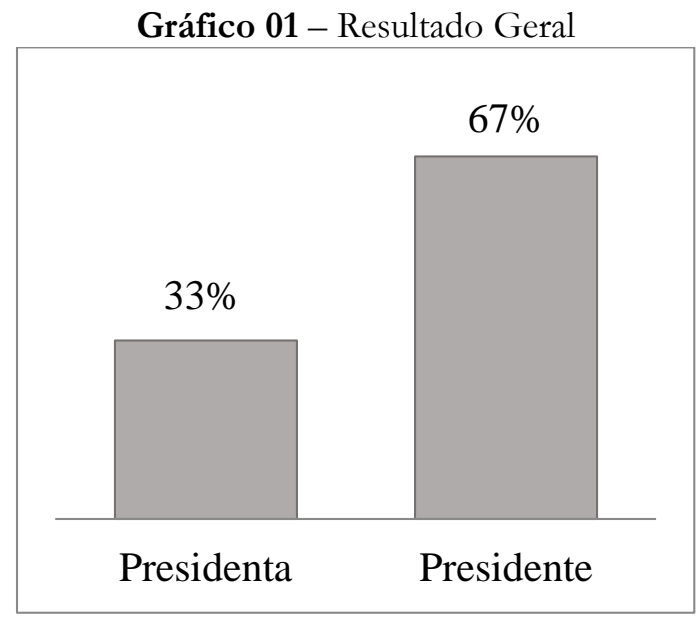

Fonte: Dados da pesquisa.

Conforme os dados acima, verifica-se que o uso de presidente supera o de presidenta nas respostas dos informantes. Como se sabe, trata-se de variantes linguísticas que "[...] são, portanto, diversas maneiras de se dizer a mesma coisa em um mesmo contexto, e com o mesmo valor de verdade" (TARALLO, 1985, p. 8).

Salienta-se que dos 16 inquéritos em que se consideraram como resposta o item presidente para designar a mulher que ocupa o cargo da Presidência da República, seis informantes citaram presidenta no decorrer de suas respostas, representando um percentual de $38 \%$ do total dos 16 informantes e $25 \%$ do total dos 24 informantes. Com isso, podemse apresentar os resultados como explicitados no quadro 02 , em que se verifica que, ainda assim, a forma presidente possui um percentual maior de ocorrência que presidenta.

Quadro 02 - Resultado Geral II

\begin{tabular}{|c|c|c|}
\hline ITEM & OCORRÊNCIA & PORCENTAGEM \\
\hline Presidenta & 08 & $33 \%$ \\
\hline Presidente & 10 & $42 \%$ \\
\hline $\begin{array}{c}\text { Presidente e } \\
\text { Presidenta }\end{array}$ & 06 & $25 \%$ \\
\hline Total & 24 & $100 \%$ \\
\hline
\end{tabular}

Fonte: Dados da pesquisa.

Para melhor ilustrar essas ocorrências, apresentam-se os excertos de inquéritos em que, nas respostas de presidente, os informantes citaram presidenta.

i. Informante masculino, faixa etária II, nível de escolaridade universitária, de

Florianópolis diz ouvir outras pessoas usarem presidenta, mas define o seu uso como presidente. Confira exemplo abaixo.

INQ.- Se na presidência da república estivesse uma mulher ela seria...

INF.- (...).

INQ.- Ela seria o quê?

INF.- (...) presidente da república eu acho que se usa o masculino agora (inint) eu vejo alguém

usar presidenta...

INQ.- Oi?

INF.- Eu vejo alguém usar presidenta.

INQ.- Quem que usa?

INF.- Eu já vi algumas pessoas. 
INQ.- Mas o senhor fala como?

INF.- É presidente.

ii. No exemplo 02, consta a resposta do informante masculino, faixa etária I, nível de escolaridade universitário, de Curitiba que fala presidente e tem dúvida da validade do uso de presidenta.

INQ.- E se na presidência da República estivesse uma mulher. Ela seria o quê?

INF.- Aí é um problema né? Porque, parece que existe a palavra presidenta mais eu acho que é presidente mesmo.

No quadro 03, apresenta-se o perfil dos informantes que em suas respostas informaram o uso de presidente, mas citaram o vocábulo presidenta.

Quadro 03 - Respostas: presidente com citação de presidenta

\begin{tabular}{|c|c|c|}
\hline \multirow{2}{*}{ RESPOSTA } & CIDADE & $\begin{array}{c}\text { CARACTERÍSTICAS DO } \\
\text { INFORMANTE }\end{array}$ \\
\hline \multirow{4}{*}{ Presidente/Presidenta } & Curitiba & Homem, Faixa I, Universitário \\
\cline { 2 - 3 } & Curitiba & Mulher, Faixa II, Universitário \\
\cline { 2 - 3 } & Florianópolis & Homem, Faixa I, Universitário \\
\cline { 2 - 3 } & Florianópolis & Homem, Faixa II, Universitário \\
\cline { 2 - 3 } & Porto Alegre & Mulher, Faixa I, Universitário \\
\cline { 2 - 3 } & Porto Alegre & Mulher, Faixa II, Universitário \\
\hline
\end{tabular}

Fonte: Dados da pesquisa.

Fazendo uma leitura do quadro 03, vê-se que em cada cidade houve dois informantes que citaram presidenta embora tenham dito que utilizavam presidente, perfazendo um total de seis informantes de escolaridade universitária, subdivididos em três homens e três mulheres, sendo três da faixa etária I e três da faixa etária II. Em Florianópolis, os dois representantes são do sexo masculino e, em Porto Alegre, os dois são do sexo feminino, mas em Curitiba ocorreu na resposta de um informante do sexo masculino e de um do sexo feminino.

Chama a atenção o fato de todos os informantes que citaram presidenta em suas respostas de presidente possuírem escolaridade universitária. Pensa-se que a escolaridade pode ter influenciado na citação dos dois itens lexicais no decorrer da resposta, pois esses informantes podem, por meio dos estudos, ter o conhecimento da flexão de gênero de substantivos e das possibilidades de usos desse item lexical como presidenta ou presidente. $\mathrm{Na}$ dúvida, acredita-se que optaram pelo convencional, pelo que o senso comum assumiu como normativo e pelo que, provavelmente, o colocavam no status de quem "acerta" a reposta à pergunta.

Conforme registros, os inquéritos foram realizados nessas capitais de 2001 a 2012, sendo o primeiro em Curitiba com o informante 05 - homem, faixa etária I, universitário e o último inquérito em Porto Alegre com a informante 06 - mulher faixa etária I, universitária. Segue compilação dos períodos dos inquéritos em cada capital.

Quadro 04 - Período de realização dos inquéritos

\begin{tabular}{|c|c|}
\hline CIDADES & PERÍODOS DOS INQUÉIRTOS \\
\hline Curitiba & $2001 / 2002$ \\
\hline Florianópolis & 2004 \\
\hline Porto Alegre & $2007 / 2010 / 2012$ \\
\hline
\end{tabular}

Fonte: Dados da pesquisa. 
Dos 24 inquéritos realizados, dois ocorreram após a eleição de Dilma Rousseff à presidência da República. Ambos foram realizados em Porto Alegre, com o homem — faixa I - universitário, em dezembro de 2010, e a mulher - faixa I - universitária, em abril de 2012. Vejam-nos no quadro 05.

Quadro 05 - Inquéritos realizados após eleição presidencial

\begin{tabular}{|l|c|}
\hline INFORMANTES & DATAS DOS INQUÉRITOS \\
\hline Homem - Faixa I - Universitário & $21 / 12 / 2010$ \\
\hline Mulher - Faixa I - Universitário & $20 / 04 / 2012$ \\
\hline
\end{tabular}

Fonte: Dados da pesquisa.

No inquérito realizado em 2010, com o homem, a resposta foi a presidente. "Eu chamo de presidente. A presidente".

No inquérito realizado em 2012, com a mulher, a reposta foi a presidente do Brasil, com citação de a presidenta:

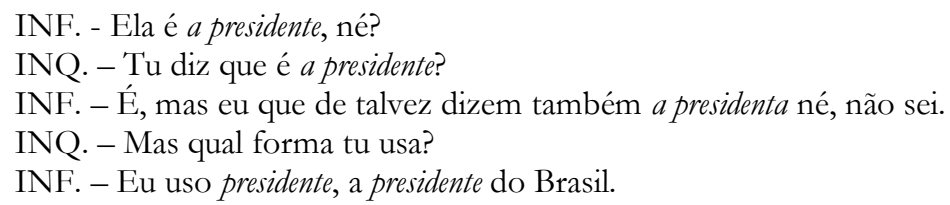

Como se vê, ambas as respostas consideradas foram presidente, contudo verifica-se na resposta da informante do inquérito de 2012 a realização de presidenta como uma possibilidade de uso, embora assuma utilizar presidente. Provavelmente a discussão nacional em torno do assunto tenha influenciado a informante a citar o item presidenta e a ter escolhido presidente.

Para os oito informantes que utilizaram presidenta como resposta, sete indicaram prontamente esse item, sem hesitação, inclusive, ratificando-o quando o inquiridor tentava confirmar a resposta. Confira com o exemplo da entrevista com a informante feminina, faixa etária I, ensino fundamental, de Curitiba.

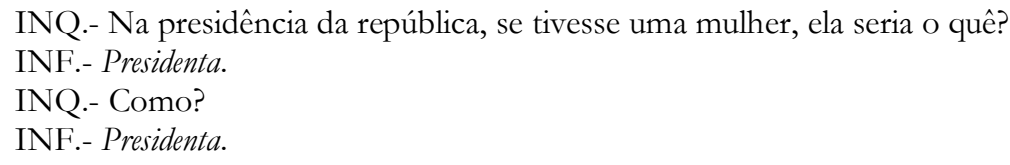

Contudo, o informante masculino, de faixa etária II, de nível de escolaridade fundamental de Curitiba mencionou unicamente a forma presidenta em sua resposta, mas não confirmou o seu uso para designar o cargo de quem ocupa a presidência do Brasil. Todavia, observa-se que há um problema na formulação da pergunta ao ser realizada pelo inquiridor, visto que citou no início da formulação o item presidente: "INQ.- Se, por hipótese a Roseana se eleger presidente, a gente vai dizer que ela vai ser ... do Brasil? Vai ser o quê do Brasil? Vai ser..." O pronunciar da forma presidente na pergunta pode ter influenciado o informante a não ter certeza do uso da única forma que citou três vezes em sua resposta: presidenta. Além disso, o inquiridor reforçou a dúvida do informante dizendo: "Não sei como é que pode ficar, né?". Assim, o informante não afirmou o seu uso como presidenta, mas também não citou a outra forma linguística em questão. Considerou-se a resposta presidenta como válida para este inquérito realizado com informante masculino, faixa II, ensino fundamental, de Curitiba. Segue-se a transcrição.

INQ.- Se, por hipótese a Roseana se eleger presidente, a gente vai dizer que ela vai ser... do Brasil? Vai ser o quê do Brasil? Vai ser... 
INF.- Agora vai ser o que uma.... como é que pode se pronunciar? Presidenta não... presidenta acho que não, não existe essa...

INQ.- Não sei como é que pode ficar, né?

INF.- Pode ser o quê, uma governanta do... governanta também não que governanta que trabalha em casa de família, (risos) mas aí vai ter que ser mais ou menos nesses termo aí, governanta dum país, vai... acredito que é mais ou menos nesses termos, porque presidenta também num.

INQ.- Parece que a gente num está acostumado com a palavra ainda, né? Mas tem um...

INF.- Porque teve outro país que tava...

INQ.- Na Finlândia é uma mulher que manda.

INF.- É mas eu não tô lembrado qual... qual é a pronúncia pra esse cargo assim, não.

$\mathrm{Na}$ análise dos dados, deve-se levar em consideração que a metodologia de obtenção de resposta do $\mathrm{ALiB}$ se deu por meio de entrevistas em que se aplicou um questionário no qual se tem "(...) como ponto positivo, a uniformidade dos dados obtidos, ou seja, a utilização das mesmas questões para todos os informantes". (ARAGÃO, 2003, p. 64). Dessa maneira, essa uniformidade na aquisição dos dados coletados pelo ALiB garante que todos os informantes tenham se submetido à mesma situação de fala para que apresentem a sua resposta às questões. O QMS possui 49 questões, das quais 07 são sobre gênero, estando entre elas a que se refere a presidente.

Importa destacar que o QMS é aplicado “[...] quase no final da entrevista, após 159 perguntas do QFF (Questionário Fonético Fonológico), 11 questões de Prosódia e 202 do QSL (Questionário Semântico Lexical).” (CASTRO, 2003, p. 90). A esta altura da entrevista, como ponto positivo, supõe-se já haver uma intimidade do informante com o questionário, assim "[...] informante e entrevistador certamente já estarão mais à vontade na presença um do outro, desenvolvendo provavelmente uma interação mais afinada e mais fluente. " (CASTRO, 2003, p. 90).

Apresentam-se, a seguir, as informações que nos permitirão inferir a respeito da variação diassexual, diastrática, diageracional e diatópica no uso das formas presidente e presidenta.

\subsection{A VARIÁVEL SEXO}

Em relação aos dados dos informantes divididos por sexo, vemos que o resultado foi exatamente igual para homens e mulheres: prevaleceu o uso de presidente em $67 \%$ dos casos, enquanto $33 \%$ utilizaram presidenta. Houve uma vantagem de $50 \%$ de um para outro, pois das 12 entrevistas de cada tipo de falantes, quatro citaram presidenta e 08 citaram presidente como resposta, ou seja, a ocorrência de presidente é o dobro da de presidenta. Diante do resultado, vê-se que os homens e as mulheres pesquisados apresentaram igual preferência no uso de presidente em detrimento ao de presidenta, não havendo, portanto, a indicação de variação diassexual para o emprego desses itens.

\begin{tabular}{|c|c|c|c|}
\multicolumn{3}{c|}{ Quadro 06 - Variável Sexo } \\
\cline { 2 - 4 } ITEM & \multicolumn{3}{|c|}{ SEXO } \\
\hline Masculino & Feminino & $\%$ \\
\hline Presidente & 8 & 8 & $67 \%$ \\
\hline Presidenta & 4 & 4 & $33 \%$ \\
\hline Total & 12 & 12 & $100 \%$ \\
\hline
\end{tabular}

Fonte: Dados da pesquisa. 


\subsection{A VARIÁVEL ESCOLARIDADE}

Para o estudo das variantes presidente e presidenta, vê-se no eixo escolaridade um comportamento distinto entre os falantes do ensino fundamental e os do ensino universitário.

Os informantes de ensino fundamental igualaram o resultado, apresentando seis ocorrências para cada variante, o que indica que 50\% deles escolheram um item e $50 \%$ o outro. Já os falantes com escolaridade universitária revelaram um alto índice de uso para presidente em detrimento de presidenta: foram 10 ocorrências para o primeiro e duas ocorrências para o segundo.

Em termos percentuais, os informantes de escolaridade universitária apresentam um resultado de $83 \%$ para presidente e $17 \%$ para presidenta. Observam-se essas ocorrências no gráfico 02 .

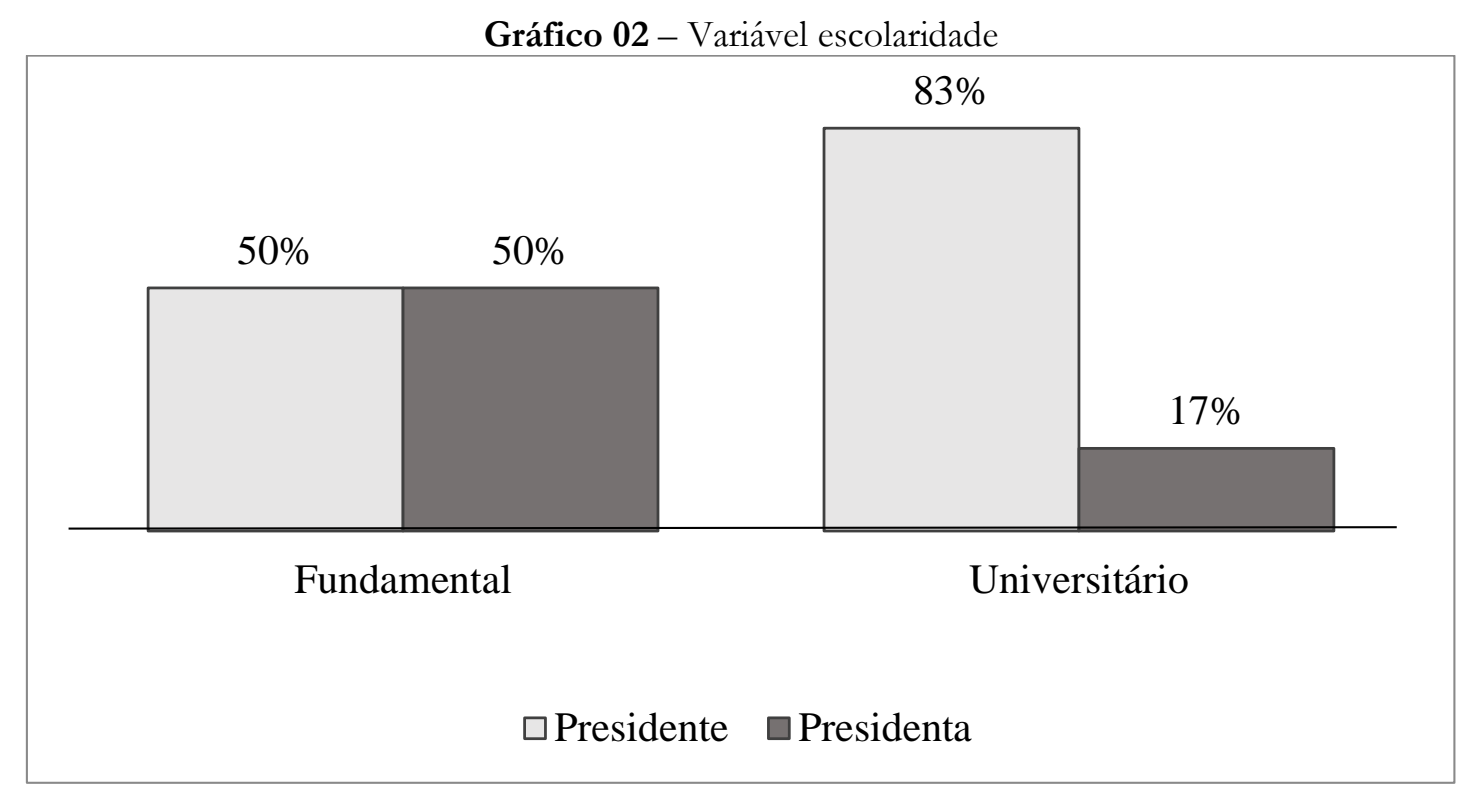

Fonte: Dados da pesquisa.

\subsection{AS VARIÁVEIS SEXO E ESCOLARIDADE}

É importante visualizar os resultados obtidos no cruzamento das variáveis sexo e escolaridade, como se pode verificar no Quadro 07.

Quadro 07 - Variável Sexo X Variável Escolaridade

\begin{tabular}{|c|c|c|c|c|}
\hline \multirow{2}{*}{ ITEM } & \multicolumn{4}{|c|}{ SEXO X ESCOLARIDADE } \\
\cline { 2 - 5 } & $\begin{array}{c}\text { Homem } \\
\text { Fund. }\end{array}$ & $\begin{array}{c}\text { Mulher } \\
\text { Fund. }\end{array}$ & $\begin{array}{c}\text { Homem } \\
\text { Univ. }\end{array}$ & $\begin{array}{c}\text { Mulher } \\
\text { Univ. }\end{array}$ \\
\hline Presidente & 3 & 3 & 5 & 5 \\
\hline Presidenta & 3 & 3 & 1 & 1 \\
\hline Total & 6 & 6 & 6 & 6 \\
\hline
\end{tabular}

Fonte: Dados da pesquisa.

Observa-se, no quadro 07, que há um equilíbrio entre os usos de homens e mulheres tanto do ensino fundamental quanto do ensino universitário. Com isso, vê-se nos 
informantes em questão uma variação diassexual equilibrada para presidente e presidenta, já que homens e mulheres apresentam um resultado comparativamente estável. A distinção de resultado é mais elevada na ocorrência desses itens na variação diastrática, especificamente, nos informantes de escolaridade universitária, em que presidente se sobressai, como foi apresentado também no gráfico 02 .

\subsection{AS VARIÁVEIS SEXO E FAIXA ETÁRIA}

Com o objetivo de realizar um estudo em tempo aparente, foi verificada a variação diageracional nos usos das variantes presidente e presidenta em informantes de duas faixas etárias em um mesmo período linguístico. Como se pode verificar no quadro 08, a faixa etária I apresenta 10 ocorrências para presidente, sendo cinco dos homens e cinco das mulheres, representando $83 \%$ das respostas e dois para presidenta, representando 17\% das ocorrências, enquanto a faixa II apresenta seis ocorrências para cada forma vocabular. Verifica-se, portanto, que os informantes mais jovens preferiram utilizar em suas respostas presidente a presidenta, enquanto os mais velhos se dividiram na preferência, pois houve seis ocorrências para cada item, sendo três para os homens e três para as mulheres. No Gráfico 03 verificase a distribuição das respostas por faixa etária e no Quadro 08, por faixa e por sexo.

Levando em consideração o contexto, em que a mídia utiliza de forma maciça o sintagma a presidente, pode-se considerar que essa forma ganha, gradativamente, prestígio em detrimento a presidenta, que é relacionado ao uso impositivo da presidência e de seus adeptos partidários. Mas, como nos diz Tarallo (1985, p. 12), não há nada inerente a essas variantes que as definam como boas, ruins, corretas ou incorretas. "Trata-se somente de uma questão de atitude sociolinguística dos membros de uma comunidade". Inclui-se a essa reflexão, o fato de que ainda não se pode atribuir a um uso ou outro a classificação distintiva de norma culta ou popular. O fato de os informantes da faixa I - homens e mulheres - apresentarem, prioritariamente, em suas respostas a forma presidente indica uma preferência dos informantes mais jovens da pesquisa, de ambos os sexos, como se pode ver no quadro 08 e no gráfico 03. Já os da faixa II dividem a escolha, pois $50 \%$ dos informantes apresentaram presidente como resposta, ficando os outros $50 \%$ com a forma presidenta; nesse caso, vê-se um equilíbrio no uso de ambas variantes.

No gráfico 03, pode-se melhor visualizar a representação das respostas dos informantes divididos por faixas etárias (I e II) e ratificar a superioridade de ocorrência do item presidente. Mas ainda não podemos falar em indícios de mudança linguística, pois se acredita que essa afirmação só poderá ocorrer com uma pesquisa em maior escala, envolvendo os inquéritos do ALiB em todo o Brasil, tanto das capitais como das cidades do interior.

Gráfico 03 - Variável Faixa Etária

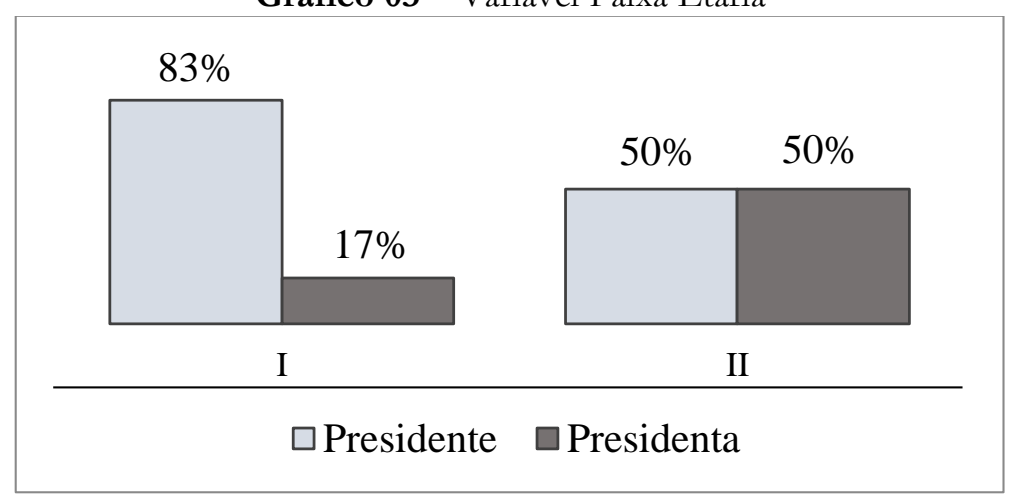

Fonte: Dados da pesquisa. 
Quadro 08 - Variável Sexo X Variável Faixa Etária

\begin{tabular}{|c|c|c|c|c|}
\hline \multirow{2}{*}{ ITEM } & \multicolumn{4}{|c|}{ SEXO X FAIXA ETÁRIA } \\
\cline { 2 - 5 } & $\begin{array}{c}\text { Homem } \\
\text { Faixa I }\end{array}$ & $\begin{array}{c}\text { Mulher } \\
\text { Faixa I }\end{array}$ & $\begin{array}{c}\text { Homem } \\
\text { Faixa II }\end{array}$ & $\begin{array}{c}\text { Mulher Faixa } \\
\text { II }\end{array}$ \\
\hline Presidente & 5 & 5 & 3 & 3 \\
\hline Presidenta & 1 & 1 & 3 & 3 \\
\hline Total & 6 & 6 & 6 & 6 \\
\hline
\end{tabular}

Fonte: Dados da pesquisa.

\subsection{AS VARIÁVEIS FAIXA ETÁRIA E ESCOLARIDADE}

No quadro 09, pode-se verificar a distribuição das respostas dos informantes divididos por faixa etária e escolaridade. Observa-se que as duas respostas registradas para presidenta na faixa etária I foram apresentadas pelo informante do ensino fundamental enquanto que os informantes dessa faixa etária e de escolaridade universitária apresentaram $100 \%$ do uso para presidente. $\mathrm{Na}$ faixa etária II, os informantes do ensino fundamental apresentaram quatro ocorrências para presidenta, correspondendo a $67 \%$ de preferência, esse mesmo resultado e índice percentual se deram para presidente nos informantes da faixa II com escolaridade universitária. Pode-se concluir com os dados do Quadro 09 que informantes da faixa I preferiram presidente, assim como os informantes de escolaridade universitária.

Quadro 09 - Variável Faixa Etária X Variável Escolaridade

\begin{tabular}{|c|c|c|c|c|}
\hline \multirow{2}{*}{ ITEM } & \multicolumn{4}{|c|}{ FAIXA ETÁRIA X ESCOLARIDADE } \\
\cline { 2 - 5 } & $\begin{array}{c}\text { Fund. } \\
\text { Faixa I }\end{array}$ & $\begin{array}{c}\text { Univ. } \\
\text { Faixa I }\end{array}$ & $\begin{array}{c}\text { Fund. } \\
\text { Faixa II }\end{array}$ & $\begin{array}{c}\text { Univ. } \\
\text { Faixa II }\end{array}$ \\
\hline Presidente & 4 & 6 & 2 & 4 \\
\hline Presidenta & 2 & 0 & 4 & 2 \\
\hline Total & 6 & 6 & 6 & 6 \\
\hline
\end{tabular}

Fonte: Dados da pesquisa.

\subsection{A VARIAÇÃO DIATÓPICA}

No eixo diatópico, verifica-se que a cidade de Florianópolis se destaca no uso de presidente com um percentual de $88 \%$ da escolha dos informantes; a preferência também ocorreu em Porto Alegre com um índice de 63\%. Em Curitiba, a ocorrência de ambas as formas vocabulares se deu com $50 \%$ para cada uma.

Salienta-se que a única resposta de presidenta em Florianópolis partiu de um informante do sexo feminino, faixa II, com escolaridade universitária. Essa informante apresenta sua resposta sem qualquer dúvida a respeito do uso, como se pode observar no trecho do inquérito: "INQ.- Se na presidência da República estivesse uma mulher ela seria o quê? INF.Presidenta."

Observa-se no gráfico 04 a representação gráfica da distribuição diatópica de presidente e presidenta nas três capitais estudadas, verificando-se que em Florianópolis e em Porto Alegre houve maior incidência de respostas para presidente que para presidenta e em Curitiba ocorreu um empate nas repostas apresentadas pelos informantes. 
Gráfico 04 - Variável Diatópica

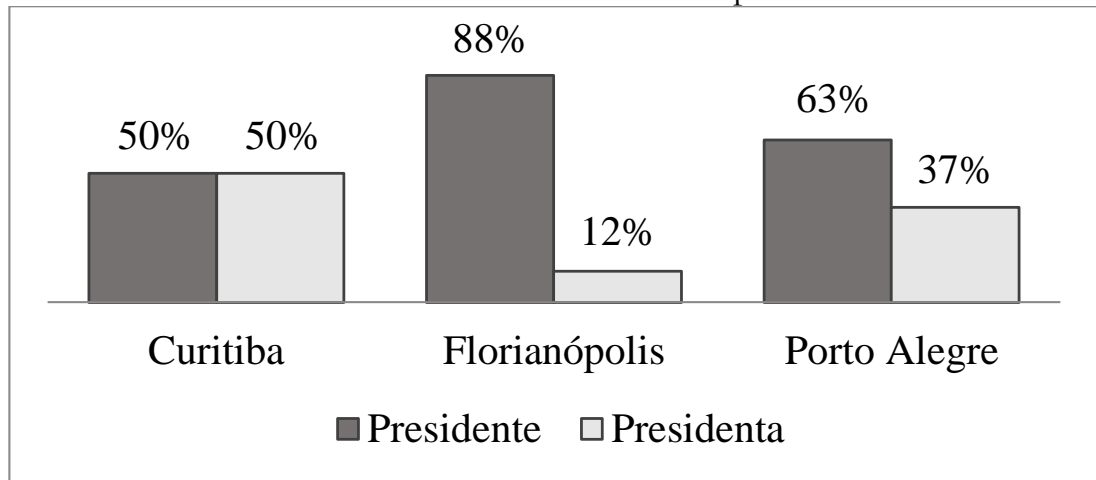

Fonte: Dados da pesquisa.

\section{UM ESTUDO DE PRESIDENTE E PRESIDENTA NO NORDESTE DO BRASIL}

Santana (2015), em sua dissertação de mestrado, intitulada "O gênero na região Nordeste: morfologia e estigma social", fez um estudo sobre os morfemas que determinam o gênero feminino em alguns vocábulos, dentre eles em presidente, utilizando os dados do projeto $\mathrm{ALiB}$, em 77 localidades na região Nordeste do Brasil, em que foram selecionados 344 informantes.

Os resultados dessa pesquisa revelam que 59,6\% dos informantes apresentaram como primeira resposta à pergunta 09 do QMS a forma presidente, aceitando-a como um item comum de dois gêneros, conforme as classificações da gramática normativa. Já 33,4\% dos informantes utilizaram a forma flexionada presidenta como resposta para se referirem à mulher que estivesse na Presidência da República. Os 7\% restantes foram respostas com outras designações.

Em seu estudo, a pesquisadora teve o cuidado de analisar os inquéritos realizados pela equipe do ALiB no período pós eleição de Dilma Roussef para presidência, ocorridos a partir de 2011, com objetivo de verificar se os informantes manifestaram preferência pelo uso, como resposta ao questionário, da forma marcada com o morfema de gênero: presidenta, "[...] já que houve uma mobilização quanto ao uso da forma presidenta [...]". (SANTANA, 2015, p.115). Para isso, foram analisados 74 inquéritos pertencentes a 20 localidades e o resultado foi o seguinte: $71 \%$ dos informantes apresentaram presidente como resposta, $26 \%$ apresentaram presidenta e 3\% não apresentaram resposta, portanto "não houve aumento no uso da variante presidenta após o início do mandato de uma mulher na presidência da república”. (SANTANA, 2015, p. 119).

Por fim, a autora da dissertação conclui que

Esses dados corroboram com a hipótese de que embora após sua eleição a presidenta Dilma Roussef tenha tentado estabelecer a forma presidenta na língua, não há indício que leve a crer que a forma irá, de fato, se fincar como forma corrente. (SANTANA, 2015, p. 120).

\section{CONSIDERAÇÕES FINAIS}

Pode-se concluir que dos 24 informantes participantes da pesquisa do ALiB, especificamente nas capitais da região Sul, 16 apresentaram presidente como resposta e oito apresentaram presidenta. Das 16 respostas para presidente, seis citaram a variante presidenta, mas foram definidas suas respostas como presidente. 
Os inquéritos linguísticos foram realizados no período de 2001 a 2012 e ocorreram por meio de entrevistas com a utilização de um questionário, a partir do qual se obtiveram as respostas de todos os informantes. Do total de inquéritos realizados, apenas dois ocorreram após a eleição de Dilma Rousseff. Diante das respostas dos informantes, pôde-se fazer uma análise dos dados considerando as dimensões sexo, escolaridade, faixa etária e ainda a dimensão diatópica. Levando em consideração essas dimensões, verificaram-se os usos das variantes presidente e presidenta e concluiu-se que: i. homens e mulheres apresentam o mesmo resultado para os usos das variantes, não havendo destaque para resultados distintamente significativos na variação diassexual; ii. na variável diastrática, os informantes universitários apresentaram em suas respostas uma diferença de uso entre presidente (83\%) e presidenta (17\%), já que os de nível fundamental apresentaram um equilíbrio quantitativo das variantes (50\%); iii. em relação à variação diageracional, os informantes da faixa etária I apresentaram em suas respostas maior diferença entre as variantes, presidente (83\%) e presidenta $(17 \%)$ que os informantes de faixa II, cujo resultado dos usos das variantes é equilibrado (50\%). Destacam-se os informantes universitários da faixa I que foram unânimes ao apresentar presidente como resposta; iv. na variação diatópica, Curitiba apresenta um resultado equilibrado nas respostas dos informantes, enquanto em Florianópolis e em Porto Alegre predomina como resposta a variante presidente.

Diante do estudo das variantes presidente e presidenta, verifica-se que tanto nas gramáticas e dicionários quanto nas respostas dos informantes do ALiB, das capitais da região Sul, encontram-se as duas variantes. Mesmo o corpus indicando um maior índice de ocorrência para presidente, vê-se o uso significativo de presidenta, já que em algumas variáveis há uma ocorrência de $50 \%$ para esse item. Pode-se concluir que os itens estabelecem entre si o status de variantes que possuem o mesmo valor de verdade. Coadunando com os resultados desta pesquisa realizada na região Sul do Brasil, Santana (2015) conclui que na região Nordeste a preferência dos informantes também é por presidente.

Dessa forma, vê-se que o estudo de presidente e presidenta pode e deve ser realizado com os dados do ALiB nas outras regiões do país, a fim de que se possa ter um retrato linguístico da flexão ou não da forma presidente no português falado no Brasil.

\section{REFERÊNCIAS}

ARAGÃO, Maria do Socorro Silva de. Avaliação dos procedimentos metodológicos nas entrevistas definitivas: os questionários. In: AGUILERA, Vanderci; MOTA, Jacyra; MILANI, Gleydy (Orgs.). Documentos 1 (Atlas Linguístico do Brasil), Salvador: ILUFBA/ EDUFBA, 2003.

BAGNO, Marcos. Gramática Pedagógica do Português Brasileiro. São Paulo: Parábola Editorial, 2011.

BECHARA, Evanildo. Moderna Gramática Portuguesa. 37. ed. rev. e ampl. Rio de Janeiro: Nova Fronteira, 2009.

BRASIL. Palácio do Planalto. Presidência da República Mensagem ao Congresso Nacional. Portal do Planalto, Brasília, 01 jan. 2005. Disponível em: $<$ http://www2.planalto.gov.br/acompanhe-o-planalto/mensagem-aocongresso/mensagem-ao-congresso-nacional-2013-2005>. Acesso em: 05 nov. 2015. 
CASTRO, Vandersi Sant'Ana. Avaliação dos procedimentos metodológicos das entrevistas definitivas: o questionário morfossintático (QMS). In: AGUILERA, Vanderci; MOTA, Jacyra; MILANI, Gleydy (Orgs.). Documentos 1 (Atlas Linguístico do Brasil), Salvador: ILUFBA/EDUFBA, 2003. p. 77-90.

COMITÊ NACIONAL DO PROJETO ALiB. Atlas Linguistico do Brasil. Questionários. Londrina: Editora da UEL, 2000.

CUNHA, Celso; Cintra Lindley. Nova Gramática do Português Contemporâneo. 2. ed. Rio de Janeiro: Nova fronteira, 1985.

PRESIDENTE, PRESIDENTA. In: HOUAISS, Antônio. Grande dicionário Houaiss da língua portuguesa. Dicionário eletrônico. Disponível em: <http://houaiss.uol.com.br/busca?palavra=>. Acesso em: 12 jun. 2015.

PRESIDENTE, PRESIDENTA. In: Michaelis Moderno Dicionário da Lingua Portuguesa. Dicionário Eletrônico: Melhoramentos, 2009. Disponível em: $<$ http://michaelis.uol.com.br/moderno/portugues/index.php?lingua=portugues- $>$. Acesso em: 12 jun. 2015.

SANTANA, Élide Elen da Paixão. O gênero na região Nordeste: morfologia e estigma social. 2015. 145 f.: il. Dissertação (Mestrado em Língua e Cultura) - Universidade Federal da Bahia, Instituto de Letras, Salvador, 2015.

SILVA, Maria Cecília Pérez de Souza; KOCH, Ingedore Grunfeld Villaça. Linguística aplicada ao português: morfologia. 12. ed. São Paulo: Cortez, 2001.

TARALLO, Fernando. A pesquisa sociolinguística. São Paulo: Ática, 1985. 